\title{
Chapter 10 \\ The Universal Thermal Climate Index \\ as an Operational Forecasting Tool \\ of Human Biometeorological Conditions \\ in Europe
}

\section{Claudia Di Napoli, Alessandro Messeri, Martin Novák, João Rio, Joanna Wieczorek, Marco Morabito, Pedro Silva, Alfonso Crisci, and Florian Pappenberger}

\begin{abstract}
In operational weather forecasting standard environmental parameters, such as air temperature and humidity, are traditionally used to predict thermal conditions in the future. These parameters, however, are not enough to describe the thermal stress induced by the outdoor environment to the human body as they neglect the human heat budget and personal characteristics (e.g. clothing). The Universal Thermal Climate Index (UTCI) overcomes these limitations by using an advanced
\end{abstract}

C. Di Napoli $(\bowtie) \cdot$ F. Pappenberger

European Centre for Medium-Range Weather Forecasts, Shinfield Road, Reading RG2 9AX, UK e-mail: claudia.dinapoli@ecmwf.int

F. Pappenberger

e-mail: Florian.Pappenberger@ecmwf.in

A. Messeri · M. Morabito

Interdepartmental Centre of Bioclimatology, University of Florence, Florence, Italy

e-mail: alessandro.messeri@unifi.it

M. Morabito

e-mail: marco.morabito@ibe.cnr.it

\section{A. Messeri}

Department of Agrifood Production and Environmental Sciences, University of Florence,

Florence, Italy

M. Novák

Czech Hydrometeorological Institute, Regional Office in Usti n.L., Usti n. L., Czech Republic

Faculty of Environment, Jan Evangelista Purkyne University, Usti n. L., Czech Republic

M. Novák

e-mail: martin.novak@chmi.cz

J. Rio · P. Silva

Portuguese Institute for Sea and Atmosphere, Lisbon, Portugal

e-mail: joao.rio@ipma.pt

P. Silva

e-mail: pedro.silva@ipma.pt

(C) The Author(s) 2021

E. L. Krüger (ed.), Applications of the Universal Thermal Climate Index

UTCI in Biometeorology, Biometeorology 4 ,

https://doi.org/10.1007/978-3-030-76716-7_10 
thermo-physiological model coupled with a state-of-the-art clothing model. Several systems have been recently developed to operationally forecast human biometeorological conditions via the UTCI, i.e. by computing UTCI from the forecasts of air temperature, humidity, wind speed and radiation as provided by numerical weather prediction models. Here we describe the UTCI-based forecasting systems developed in Czech Republic, Italy, Poland, Portugal and at the pan-European scale. Their characteristics are illustrated and their potential as warning systems for thermal hazards discussed.

Keywords Thermal health hazards $\cdot$ Heat stress $\cdot$ Cold stress $\cdot$ Forecasting $\cdot$ Universal Thermal Climate Index $\cdot$ Biometeorology $\cdot$ Preparedness

\section{Introduction}

Air temperature is the core figure of any weather forecast. It seldom is, however, the only atmospheric parameter affecting the well-being of an individual. Wind may cool down the human body by taking away its heat. Sunlight and humidity may warm it up instead by radiation exposure and by limiting sweating, respectively. Knowing how the outdoor environment influences the heat exchange between the human body and its surroundings is mandatory to make the forecasts of air temperature, wind, radiation and humidity meaningful from a physiological point of view. Being based on an advanced heat budget model, the UTCI is able to provide this knowledge as a one-dimensional biometeorological-sound measure quantifying the thermal comfort/discomfort perceived by the human body when exposed to outdoors conditions. As the World Meteorological Organisation underlines the need for national meteorological services to incorporate biometeorological forecasts into their suite of products and services offered to the public (WMO 2004), the production and dissemination of UTCI forecasts in operational mode, i.e. as a 24/7 automated process, would represent a significant advancement in this sense.

The UTCI has been extensively applied in climatological studies to investigate heat- and cold-related hazards and their negative impacts on human health, also within vulnerable groups (Nastos and Matzarakis 2012; Morabito et al. 2014; Urban and Kyselý 2014; Krzyżewska et al. 2017; Romaszko et al. 2017; Błażejczyk et al. 2018; Di Napoli et al. 2018; Skutecki et al. 2019; Urban et al. 2021 for a more detailed review, refer to Chap. 2 of this book). Less research has however focused on assessing the UTCI as a predictor tool of thermal health hazards for public weather

\footnotetext{
J. Wieczorek

The Institute of Meteorology and Water Management - National Research Institute, Warsaw, Poland

e-mail: joanna.wieczorek@imgw.pl
}

M. Morabito · A. Crisci

Institute of BioEconomy National Research Council, Florence, Italy

e-mail: alfonso.crisci@ibe.cnr.it 
services (Novák 2013). Computational power and data accessibility as well as the skill of numerical weather prediction (NWP) models have for years favoured the use of simpler standard parameters, such as air temperature and humidity, in the forecast of environmental conditions detrimental to human health. Recently, though, UTCI forecasts computed from a state-of-the-art NWP model have been shown to successfully predict thermal health hazards at different spatial and temporal scales across the globe thus demonstrating that technical capabilities are now mature for the implementation and use of the UTCI for operational purposes (Pappenberger et al. 2015).

To date, five operational forecasting systems based on the UTCI exist in Europe. They have been developed by the Czech Hydrometeorological Institute (CHMI), the Polish Institute of Meteorology and Water Management - National Research Institute (IMGW-PIB), the Portuguese Institute of the Sea and the Atmosphere (IPMA), the European Centre for Medium-Range Forecasts (ECMWF) and an Italian multiinstitute consortium composed of the Italian National Research Council - Institute of BioEconomy (IBE-CNR), the University of Florence - Centre of Bioclimatology (CIBIC) and the Laboratory of Monitoring and Environmental Modelling for Sustainable Development (LaMMA). Each system is based on the offline coupling between a NWP model and the UTCI model, i.e. forecast outputs of air temperature, humidity, wind speed and radiation from a NWP model are passed to the UTCI model for the computation of UTCI forecasts. UTCI forecasts are either location specific (point forecasts) or mapped (gridded forecasts) and extend into the future at distinct time steps (lead time). These steps are embedded within a fully automated procedure, called operational chain, that develops over three main stages. First, the forecasts generated by a NWP model for air temperature, humidity, wind speed and radiation are retrieved. Second, these forecasts are input as forcings into the UTCI model (mostly used in its operational form, Bröde et al. 2012) which produces UTCI forecasts as outputs. Third, UTCI forecasts are disseminated to end-users. This chapter describes for the first time the five UTCI-based forecasting systems that, to the authors' knowledge, are currently operational in Europe. Their characteristics are illustrated and their role as thermal hazards warning systems discussed.

\section{UTCI Forecasting Systems in Europe}

The UTCI-based forecasting systems currently operational in Czech Republic, Italy, Poland, Portugal and at the pan-European scale are here presented and described. Their main characteristics are summarised in Table 1. 
Table 1 Summary table of UTCI forecasting systems currently operational in Europe

\begin{tabular}{l|l|l|l|l|l}
\hline & $\begin{array}{l}\text { Czech } \\
\text { Republic }\end{array}$ & Italy & Poland & Portugal & Europe \\
\hline NWP model & ALADIN & GFS & GFS & ECMWF & ECMWF \\
\hline Spatial resolution & $2.3 \mathrm{~km}$ & $12 \mathrm{~km}$ & City & City & $9-18 \mathrm{~km}$ \\
\hline $\begin{array}{l}\text { Temporal } \\
\text { resolution }\end{array}$ & $1 \mathrm{~h}$ & $1 \mathrm{~h}$ & $6 \mathrm{~h}$ & $1-3 \mathrm{~h}$ & $6 \mathrm{~h}$ \\
\hline Outputs & Maps, charts & Maps & Maps & Maps, charts & Maps \\
\hline $\begin{array}{l}\text { Maximum lead } \\
\text { time }\end{array}$ & 3 days & 5 days & 2 days & 6 days & 10 days \\
\hline End-users & $\begin{array}{l}\text { National } \\
\text { weather } \\
\text { service }\end{array}$ & $\begin{array}{l}\text { General } \\
\text { public }\end{array}$ & $\begin{array}{l}\text { General } \\
\text { public, } \\
\text { National } \\
\text { weather } \\
\text { service }\end{array}$ & $\begin{array}{l}\text { General public, } \\
\text { Civil protection } \\
\text { agencies, Public } \\
\text { health } \\
\text { authorities }\end{array}$ & $\begin{array}{l}\text { Civil } \\
\text { protection } \\
\text { agencies }\end{array}$ \\
\hline $\begin{array}{l}\text { Communication } \\
\text { and dissemination } \\
\text { channel }\end{array}$ & $\begin{array}{l}\text { Internal } \\
\text { (GRIB outputs } \\
\text { and web) }\end{array}$ & $\begin{array}{l}\text { Web } \\
\text { platform }\end{array}$ & $\begin{array}{l}\text { Web } \\
\text { platform }\end{array}$ & Web platform & $\begin{array}{l}\text { Web } \\
\text { platform } \\
\text { (internal) }\end{array}$ \\
\hline
\end{tabular}

\subsection{Czech Republic}

CHMI, the national weather service for the Czech Republic, has been publishing biometeorological forecasts for the whole area of Czechia since 1994. In recent years a need had arised to build a new biometeorological forecasting system where the latest advancements in weather prediction and human biometeorology could be integrated. One of these advancements was the definition of the UTCI in 2009. Comparative studies performed against different thermal indices demonstrated the ability of the UTCI to better describe biometeorological conditions across different seasons and locations in the country (Novák 2011a, b, 2013). Following this, the UTCI was considered as the main reference parameter for the new Czech biometeorological forecasting system. The implementation of the UTCI as a forecasting tool required its operational computation from ALADIN, the NWP model currently in use at CHMI (Termonia et al. 2018). This was achieved in two phases. The first phase consisted in setting up an automated procedure for the computation of the mean radiant temperature $\left(\mathrm{T}_{\mathrm{mrt}}\right)$. The $\mathrm{T}_{\mathrm{mrt}}$ is a critical physical quantity for the calculation of the UTCI and represents how human beings experience radiation, specifically its solar (i.e. shortwave) and thermal (i.e. longwave) components. ALADIN provides forecasts of both shortwave and longwave radiation fluxes. Since 2018, those forecast fluxes have been used to routinely calculate $\mathrm{T}_{\mathrm{mrt}}$ as model output via the methodology described by Fanger (1970). The second phase consisted in including also the operational computation of the UTCI into the model. This was achieved in 2019 alongside other upgrades of ALADIN, such as a higher spatial resolution (from 4.7 to $2.3 \mathrm{~km}$ ) and a more accurate orography representation. UTCI forecasts are calculated via the operational procedure by Bröde et al. (2012). Their lead time is $54 \mathrm{~h}$ 


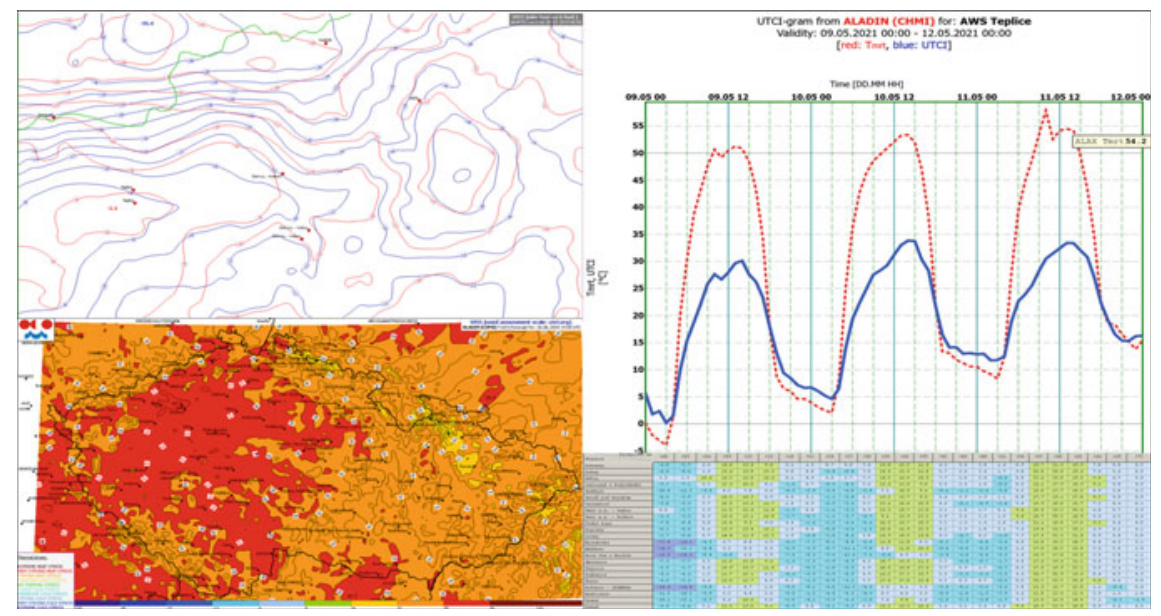

Fig. 1 Overview of UTCI forecast outputs generated by the Czech Hydrometeorological Institute. Left: fields of maximum (red lines) and minimum (blue lines) UTCI values at $6 \mathrm{~h}$ interval, UTCI mapped distribution over the Czech Republic (bottom). Right: meteogram of UTCI and $\mathrm{T}_{\mathrm{mrt}}$ at Teplice $\left(50.51^{\circ} \mathrm{N}, 13.84^{\circ} \mathrm{E}, 236 \mathrm{~m}\right.$ asl, top), table of UTCI values predicted at different Czech locations (72-h lead time, bottom). Outputs are visualised via IBL Visual Weather

(18UTC release) or $72 \mathrm{~h}(00,06,12 \mathrm{UTC}$ release). Different types of UTCI outputs are produced, from meteograms to charts and maps (Fig. 1). These are currently available to meteorologists at central and regional CHMI forecasting offices (via SW Visual Weather directly from GRIB outputs or via internal web presentation).

\subsection{Italy}

In Italy, national-level forecasts of biometeorology conditions have been limited. Since 2007, however, the Italian National Research Council - Institute of BioEconomy (IBE-CNR), the University of Florence - Centre of Bioclimatology (CIBIC) and the Laboratory of Monitoring and Environmental Modelling for Sustainable Development (LaMMA) have been joining forces to realise an operational chain for the automated production of UTCI forecasts. The chain uses air temperature, humidity, wind speed and radiation data from the Global Forecast System (GFS) refined by a Limited Area Model (LAM). The LAM downscales the four variables to a higher horizontal resolution grid $(12 \mathrm{~km})$ than GFS $(28 \mathrm{~km})$ via an improved parametrization scheme of soil and surface exchanges. The R package HeatStress has been included in the chain to calculate water vapour pressure and globe temperature (Casanueva 2019). From the latter, $\mathrm{T}_{\mathrm{mrt}}$ can be computed using the methodology described in Thorsson et al. (2007). In order to reduce computational time, specific additional procedures have been embedded. Location-specific information, 
for instance, is extracted from available stations and used to calibrate outputs by using a set of Model Output Statistics (MOS) methodologies. From January 2017, hourly UTCI forecast maps of thermal comfort/discomfort for Italy are provided with a 5-day lead time. The maps are available to the general public on a web platform (http://www.lamma.rete.toscana.it/meteo/comfort-termico, Fig. 2) and show predicted UTCI values in full sunlight or shade as well as associated frostbite risk.

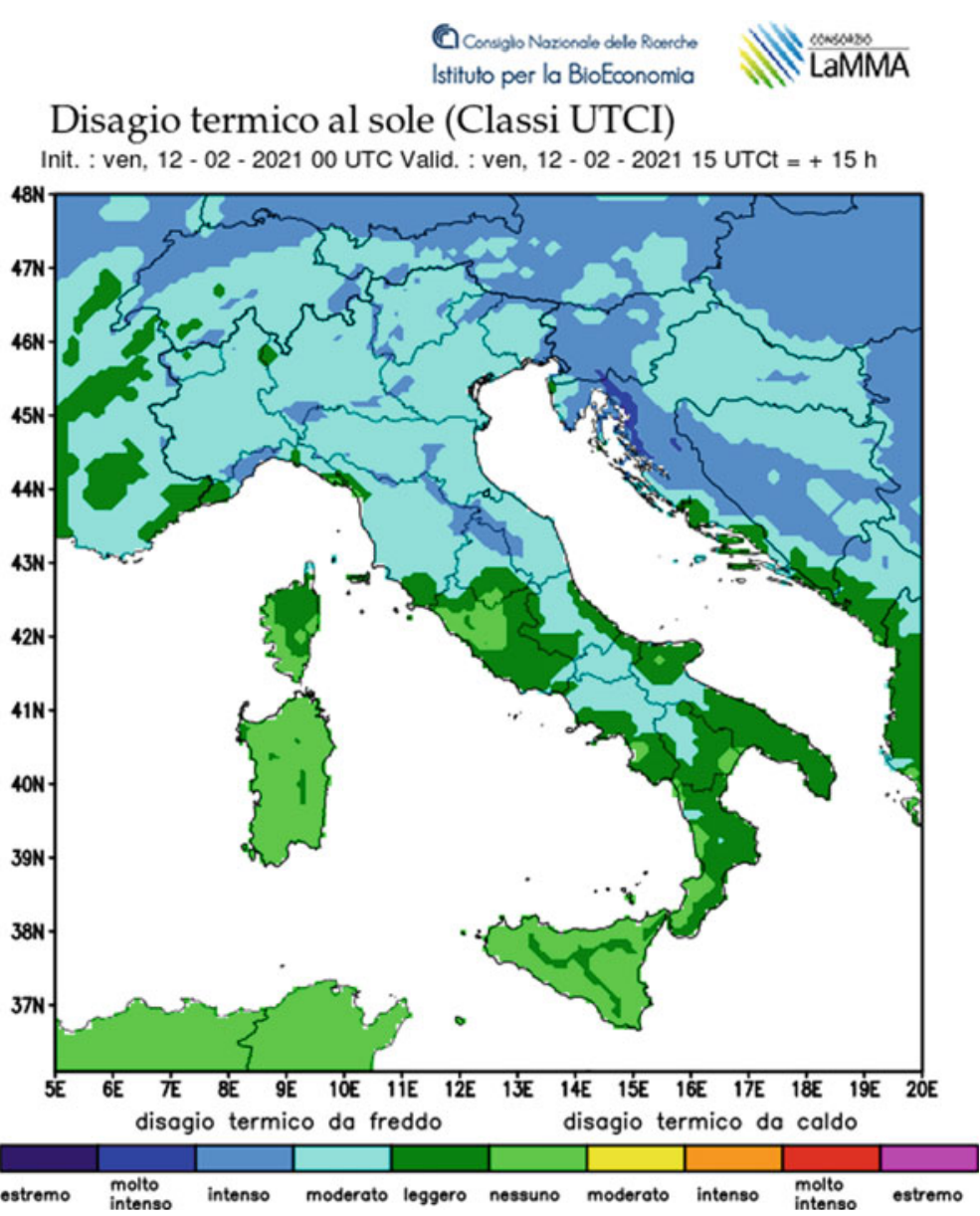

Fig. 2 Hourly UTCI forecast maps as issued for Italy by a multi-institute consortium composed of the Laboratory of Monitoring and Environmental Modelling for Sustainable Development (LaMMA), the University of Florence Centre of Bioclimatology (CIBIC) and the Italian National Research Council Institute of BioEconomy (IBE-CNR). Maps are made available to the general population via a public web platform (http://www.lamma.rete.toscana.it/meteo/comfort-termico) 


\subsection{Poland}

The implementation of the UTCI as a NWS product by the Polish meteorological service began in 2010. The UTCI is computed via application of the operational procedure described by Bröde et al. (2012) with the input parameter $\mathrm{T}_{\mathrm{mrt}}$ calculated using the procedure provided by the association of German engineers (VDI 3789 1994). Both calculations use as inputs meteorological parameters automatically derived from the GFS $0.25^{\circ}$ model. Calculations based on data from the Consortium for Small-scale Modeling (COSMO-7) are also available but are not published to the public.

The first UTCI forecast issued for the general public appeared in June during the 2012 UEFA European Football Championship. Since February 2015, UTCI forecasts are provided daily and made publicly available as the "Heat load in the human body according to the UTCI)" on the web platform of the Polish official biometeorological service (https://biometeo.imgw.pl/\%3Fpage\%3DUTCI). The service is overseen by the Polish Institute of Meteorology and Water Management - National Research Institute (IMGW-PIB). UTCI forecasts are issued for 21 major cities in Poland with a 48-h lead time ("today" and "tomorrow") and a time resolution of 6 h (Fig. 3). They are initialised each morning and expressed in terms of UTCI categories ( -5 to +4$)$. A table describes each thermal stress category, the physiological responses correspondingly induced in the human body and possible protective measures. The choice of using UTCI categories instead of the single numerical values was made in order to avoid potential misunderstandings by end-users, such as interpreting UTCI values as an apparent (feels like) temperature.

The occurrence of strong heat stress conditions $\left(32{ }^{\circ} \mathrm{C}<\mathrm{UTCI} \leq 38{ }^{\circ} \mathrm{C}\right)$ is also provided as an additional information to the Polish meteorological service. It has been observed in recent years that heatwaves start to affect Poland earlier and earlier in the spring/summer season. This poses a serious threat to local populations as they are not yet adapted to hot conditions just after winter. Specifically, the risk of mortality in the Polish population has been observed to increase more than $25 \%$ (mainly as a result of cardiovascular dysfunctions) when the UTCI is above $32{ }^{\circ} \mathrm{C}$, making this a useful threshold for the surveillance of heat stress-related health impacts (KLIMADA 2013).

\subsection{Portugal}

The Portuguese Institute for Sea and Atmosphere (IPMA) has been using the UTCI as a biometeorological tool since 2010, when the first UTCI datasets started being computed from surface observations. Climatological studies were also performed to investigate the applicability of the index in mainland Portugal (Cunha et al. 2011). In recent years, the UTCI has been operationally computed using observations, with a 


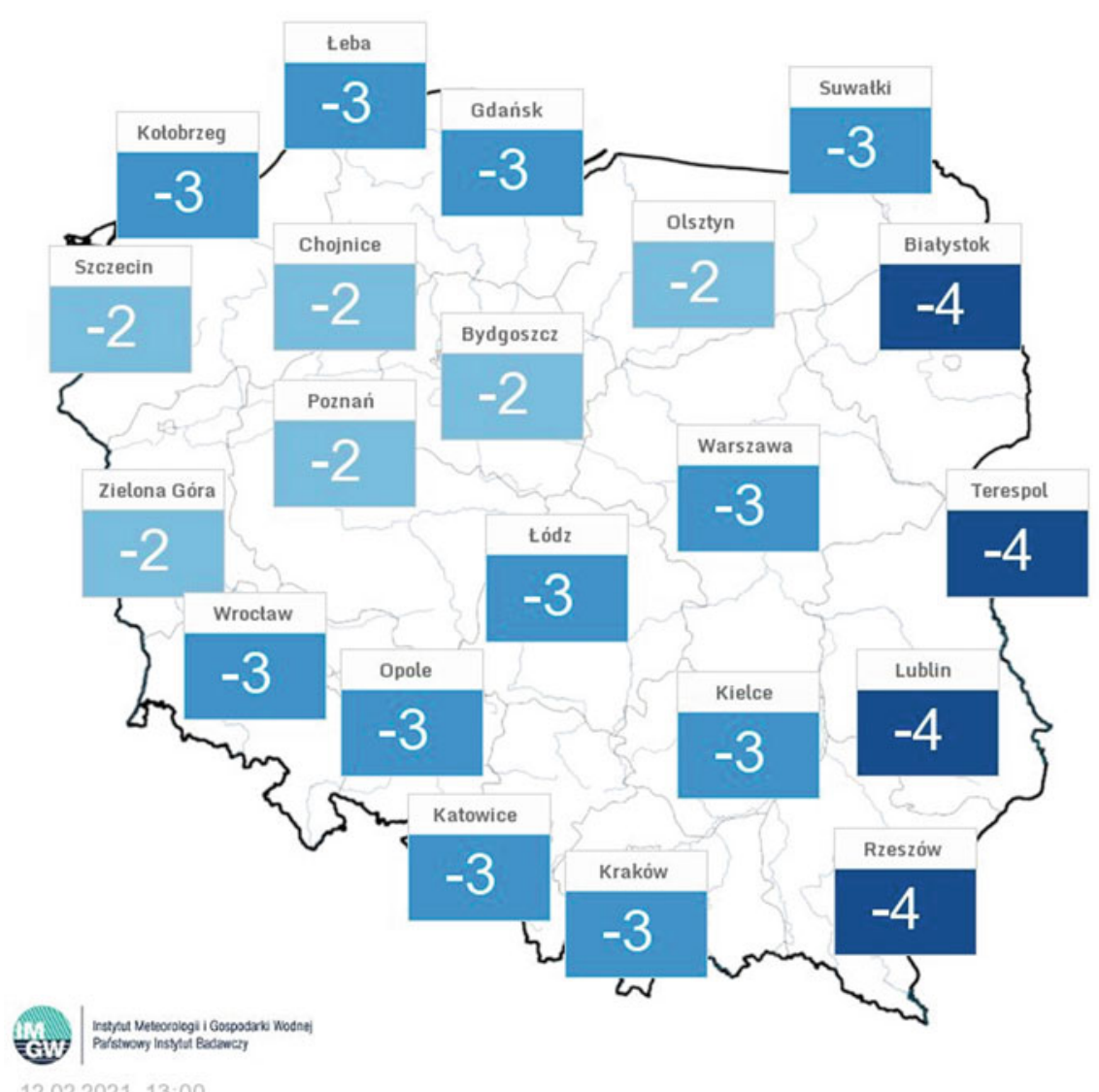

Fig. 3 City-specific UTCI forecasts as issued for Poland by the Polish Institute of Meteorology and Water Management - National Research Institute (IMGW-PIB). Forecasts are available to the general population on a public web platform (https://biometeo.imgw.pl/\%3Fpage\%3DUTCI) where protective measures are suggested for predicted UTCI categories

3-h frequency and publicly shown as maps on the IPMA official website for mainland Portugal (http://www.ipma.pt/pt/oclima/biometeo/utci/; Fig. 4a).

Currently only point UTCI forecasts are computed for around 400 locations using statistically post-processed values of $2 \mathrm{~m}$ air temperature, relative humidity and $10 \mathrm{~m}$ wind speed (Rio et al. 2018). Radiation fluxes and surface temperature are from the ECMWF high resolution forecasting model. Specifically, radiation fluxes are direct model outputs whereas surface temperature is corrected to account for differences between real and model altitudes. Location-specific UTCI forecasts are provided hourly up to $72 \mathrm{~h}$ and 3-hourly from day 4 to 6 . Whereas UTCI observational maps are available to the public, location-specific UTCI forecasts are exclusively intended for civil protection agencies and public health authorities. To these specific end-users, 
(a)

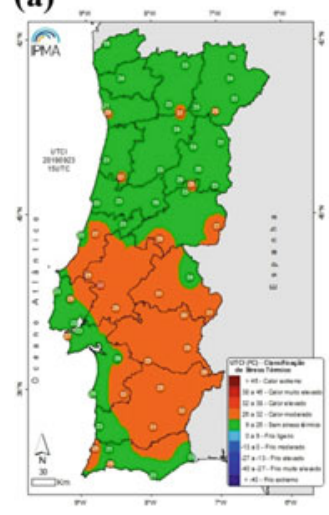

(b)

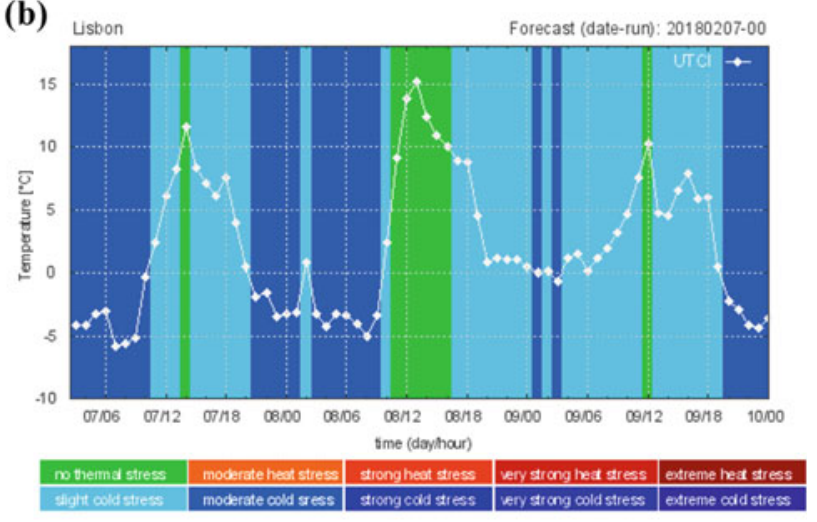

Fig. 4 Examples of UTCI forecast outputs generated by the Portuguese national meteorological centre (IPMA). Panel a Nation-wide map of the UTCI as computed from surface observations for the current day and publicly available on the IPMA website (http://www.ipma.pt/pt/oclima/bio meteo/utci/). Panel b Time series of forecast UTCI values and thermal stress categories as provided to civil protection agencies and public health authorities

the biometeorological information carried by local UTCI forecasts is presented as a time series of forecast values with color-coded intervals overlapped to allow a fast assessment of the type and duration of thermal stress periods (Fig. 4b). This information is one of the tools used by local authorities in Lisbon for the activation of emergency plans to safeguard vulnerable communities, such as the homeless.

\subsection{Europe}

Since 2016, an operational chain has been set up to deliver gridded maps of UTCI forecasts at the pan-European scale. The chain first takes as input the forecast fields of air temperature, humidity, wind and radiation as computed by the latest releases of ECMWF high resolution and ensemble models (00UTC and 12UTC). It then computes $\mathrm{T}_{\text {mrt }}$ forecasts from solar and thermal radiation fields, and finally UTCI forecasts via the operational procedure (Bröde et al. 2012; Di Napoli et al. 2020a). UTCI forecasts are issued at 6-hourly steps with a 10-day lead time. The spatial resolution is 9 or $18 \mathrm{~km}$ according to whether input parameters are from ECMWF high resolution and ensemble model, respectively. Ensemble UTCI forecasts are the mean of the 50 UTCI forecasts that are correspondingly generated using as many ECMWF ensemble forecasts.

Pan-European UTCI forecasts are currently part of a decision-support platform that aims to enhance self-preparedness to single and multiple weather-induced hazard (Horizon2020 ANYWHERE project, EnhANcing emergencY management and response to extreme WeatHER and climate Events, Grant agreement ID: 700099). 


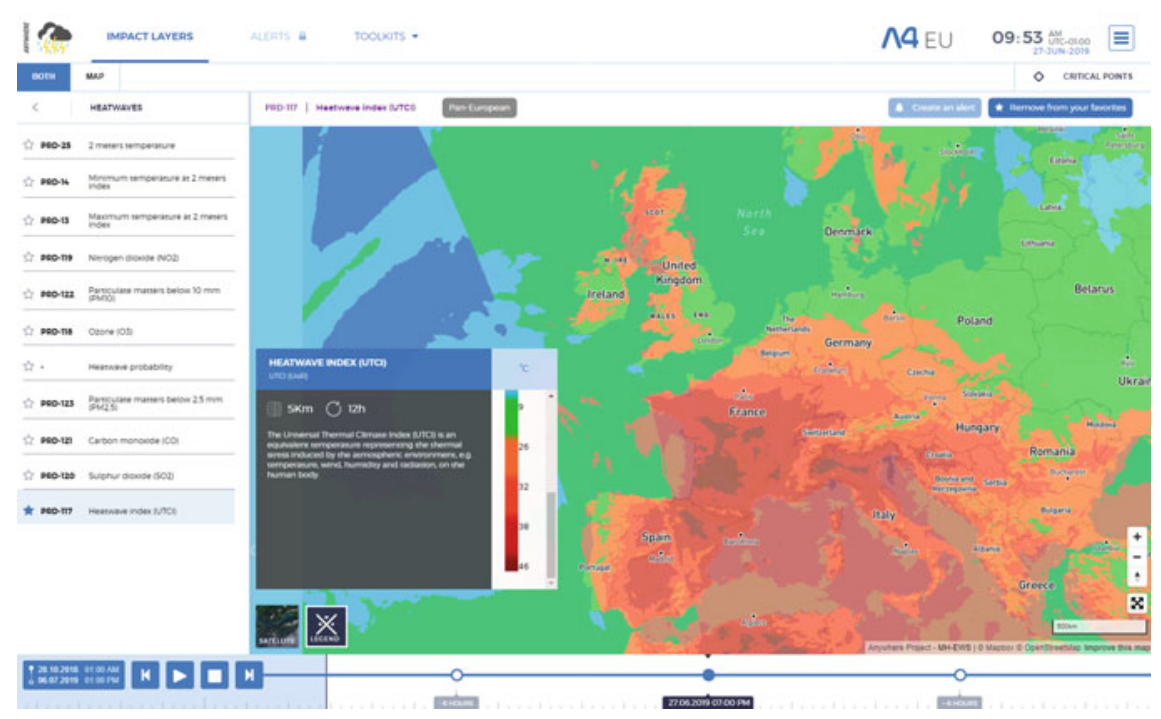

Fig. 5 Pan-European UTCI forecasts predicting the extreme thermal stress conditions achieved during the heatwave that affected the continent in June 2019

The platform is intended for civil protection agencies and local authorities only. Figure 5 shows the UTCI forecasts issued on 27 June 2019 and made available to first responders through the platform. Widespread conditions of very high and extreme heat stress were predicted in Western Europe in agreement with the intense heatwave episode affecting the area in the same period.

\section{Discussion and Perspectives}

The implementation and usage of UTCI forecasts across different European countries answer the call to integrate human thermal models with weather forecasts (Petersson et al. 2019). UTCI forecasts hence represent an opportunity to investigate the capabilities of this index to predict human thermal stress in an operational setting.

As predictors of future biometeorological conditions, the quality of UTCI forecasts needs to be assessed. This can be achieved by comparing the forecasts against observations of what actually occurred. Preliminary verification studies were carried out on UTCI forecasts issued in Poland and Czech Republic. For instance, between May and September 2018 the occurrence of strong heat stress conditions as forecast at 12 UTC in a selection of Polish cities was higher than what was correspondingly observed near IMGW-PIB stations. During a heatwave that occurred between 28 July and 10 August 2018, the difference between UTCI forecast values and UTCI observed values was up to 2 classes (Fig. 6a). In a meteorological station in the Czech 
(a)
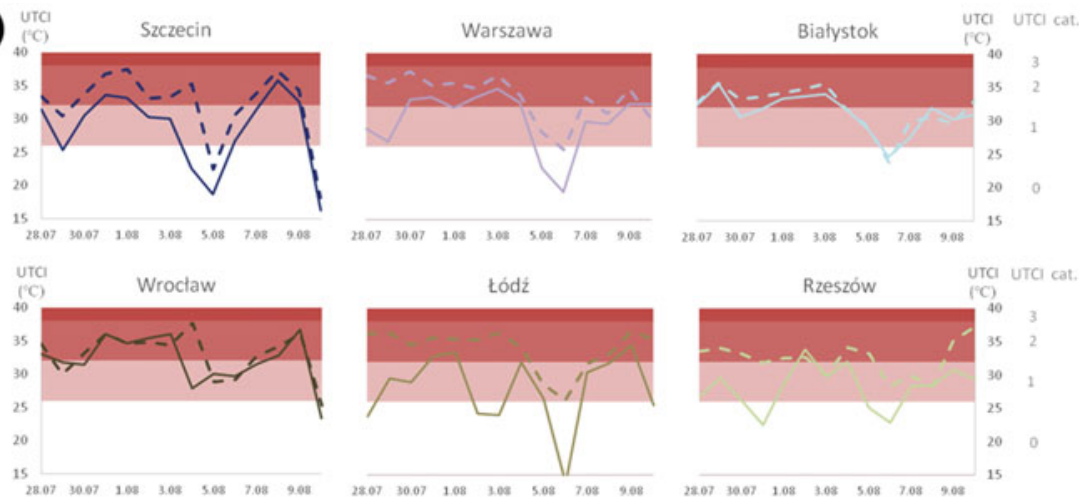

(b)

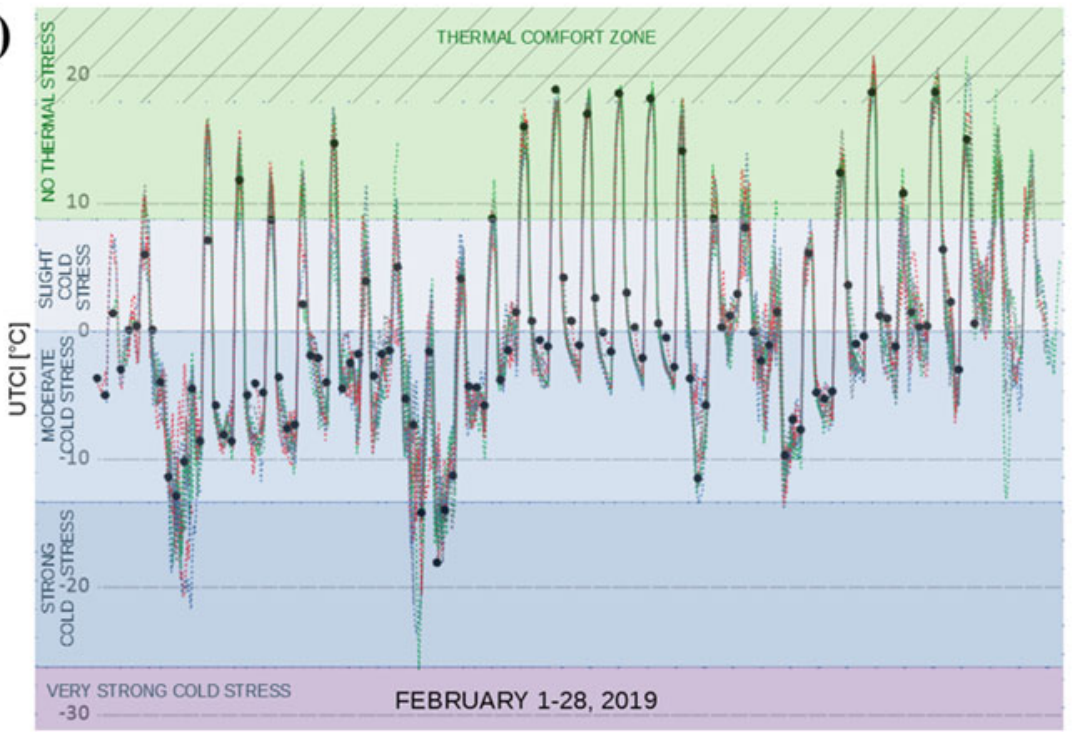

Fig. 6 Preliminary validation results for UTCI forecasts issued in Poland and Czech Republic. Panel a UTCI values at 12UTC as forecast (dashed lines) and observed ${ }^{1}$ (solid lines) at indicated Polish cities between 28 July and 10 August 2018. Panel b Time series of UTCI forecasts (dashed lines) and objective analysis (black dots) at Teplice, Czech Republic during February 2019

\footnotetext{
1 'Observed UTCI' calculations were based on historical data from telemetry and actinometrical stations of the IMGW-PIB network that are nearest to the city location. If longwave upwelling radiation and longwave downwelling radiation data (necessary to be included in the VDI procedure) were missing, the MRT values were calculated from the simplified formula of prof. Blażejczyk, which is based on measured global solar radiation data.
} 
Republic, UTCI forecast values during February 2019 were instead lower than their observed counterparts (Fig. 6b). Reanalysis data, such as ERA5-HEAT, may also be used as a proxy for observations when assessing the quality of UTCI forecasts (Di Napoli et al. 2020b).

The discrepancy between forecasts and observations can be justified by the accuracy of NWP models, namely their ability to predict atmospheric processes such as cloud formations. Cloud cover and occurrence has been shown to be underestimated at low and middle altitudes (Hogan et al. 2009). This may influence the amount of radiation reaching and leaving the surface, with a potential overestimation of radiation fluxes (Weihs et al. 2012; Di Napoli 2020b). This can be observed, for instance, in the summer season when the formation of convective clouds is characterised by great time and spatial variability. Future model developments are expected to reduce these radiation-related uncertainties. Another factor influencing the accuracy of NWP models is their spatial resolution. NWP outputs are a collection of cell-averaged values whereas station observations are collected from single point locations. One way to improve a model's ability to forecast air temperature, humidity, wind and radiation, and as a consequence $\mathrm{T}_{\mathrm{mrt}}$ and UTCI is to increase its spatial resolution. The Italian UTCI forecasting system, for example, is planned to refine from 12 to $3 \mathrm{~km}$ their grid cell size. Another way is to relate NWP outputs to observational or additional model data via statistical methods. This technique, called post-processing, is already included in the operational UTCI forecasting chain of Italy and Portugal suggesting its applicability to other countries and at the pan-European level.

Being able to communicate effectively a forecast is as important as monitoring and assessing its uncertainty. This is particularly true for UTCI forecasts. As a biometeorological tool predicting human discomfort to future environmental conditions, their ultimate purpose is to provide guidance for the safeguard of populations' wellbeing. Misinterpretation is therefore to be avoided. In Portugal, for instance, locationspecific UTCI forecasts are not available to the public. This choice has been made following the index's high sensitivity to wind speed which can lead to very negative UTCI values (e.g., $-15^{\circ} \mathrm{C}$ in Lisbon) and large differences from $2 \mathrm{~m}$ air temperature that might not be correctly interpreted by the general public. Other thermal indices are therefore disseminated on official IPMA forecasts.

In Poland, potential misunderstandings in the interpretation of UTCI forecasts have been avoided by showing a dimensionless number that corresponds to the predicted UTCI category rather than the specific UTCI numerical value expressed in ${ }^{\circ} \mathrm{C}$. This representation, reinforced by the use of a blue-white-red scale, draws the attention directly on the type of thermal (cold or heat) load local populations will be exposed to. It also recommends via a self-explanatory table which protective measures should be taken against predicted thermal loads. This has the advantage to underline the nature of UTCI forecasts as a biometeorology advisory service. On the other hand, however, this representation relies on category thresholds. Slight differences in the forecasts might be responsible for having UTCI numerical values assigned to one category instead of another. Using post-processing to integrate model forecasts with observations might help reduce the uncertainty in the category assignment. This might become of great importance particularly when UTCI thresholds are 
deployed as triggers for preparatory actions (Di Napoli et al. 2019; Shartova et al. 2019; Urban et al. 2021).

Another aspect worth noting is the communication platforms used to disseminate UTCI forecasts. These are shown on websites by four out of five operational forecasting systems here described. The widespread distribution of technology, however, suggests that other tools may also represent an effective means for communicating forecasts and associated prevention information, especially to the general public. A smartphone app, for instance, has been recently developed in the Netherlands to display in a user-friendly way city-specific UTCI forecast (Heusinkveld et al. 2017). The Italian and Polish UTCI forecasting systems will disseminate its outputs via an app as well as a web platform in their next implementation.

Using the biometeorological information carried by UTCI forecasts as a decision making tool for thermal environments detrimental to human health has been a potential field of application for the UTCI since its definition. As supported by bioclimate impact research on thermal extremes (see e.g. Basarin et al. 2020), UTCI forecasts would be useful to both the general population and target groups, i.e. outdoor workers and sportsmen as well as the vulnerable groups (e.g. the elderly). They would also help optimise emergency response to thermal extremes when these occur at the same time as other meteorological health hazards, such as wildfires (Vitolo et al. 2019).

Some of the assumptions currently at the basis of the UTCI model-fixed moderate activity level, exposure time of $2 \mathrm{~h}$, typical clothing for urban population-have however prevented the application of the UTCI in specific fields such as occupational health (NIOSH 2016). Improving the index so that it can account for the characteristics of each worker and each working activity would help make it a suitable, applicable tool for the assessment of thermal risk in the workplace too. Differently from the indices currently used in occupational heat health warning systems (e.g. wet bulb globe temperature; Morabito et al. 2019), the UTCI would be able to provide comfort/discomfort information for both heat and cold environments and on the basis of a thermo-physiological model. Given the importance of the topic, research is currently ongoing to extend the application of the UTCI to different activity levels and exposure duration (Bröde et al. 2016). This and further implementations, i.e. the effect of protective clothing in hot environments, will open the path to the UTCI as an application tool also in the occupational field (Gao et al. 2018).

\section{Conclusions}

Since its creation in 2009, the UTCI has been defined to help public weather and health services in the precautionary planning for thermal health hazards, such as heatwaves and cold spells. In recent years, the implementation of UTCI-based forecasting systems in Europe made this a reality. To date, five operational systems produce UTCI forecasts for the prediction of human comfort/discomfort conditions in the Czech Republic, Italy, Poland, Portugal and at the pan-European scale. UTCI forecasts are 
disseminated to and used by a wide range of end-users, from the general public to civil protection agencies and public health authorities. The application of UTCI forecasts by national weather services suggests that post-processing techniques can help improve the quality of the forecast and biometeorological information has to be communicated in a misinterpretation-free way.

\section{References}

Basarin B, Lukić T, Matzarakis A (2020) Review of biometeorology of heatwaves and warm extremes in Europe. Atmosphere 12:1276. https://doi.org/10.3390/atmos11121276

Błażejczyk A, Błażejczyk K, Baranowski J, Kuchcik M (2018) Heat stress mortality and desired adaptation responses of healthcare system in Poland. Int J Biometeorol 62(3):307-318. https:// doi.org/10.1007/s00484-017-1423-0

Bröde P, Fiala D, Błażejczyk K, Holmér I, Jendritzky G, Kampmann B, Tinz B, Havenith G (2012) Deriving the operational procedure for the universal thermal climate index (UTCI). Int J Biometeorol 56(3):481-494. https://doi.org/10.1007/s00484-011-0454-1

Bröde P, Kampmann B, Fiala D (2016) Extending the Universal Thermal Climate Index UTCI towards varying activity levels and exposure times. In: Proceedings of 9th Windsor conference: making comfort relevant, Cumberland Lodge, Windsor, UK, pp 73-79.

Casanueva A (2019) R Package "HeatStress". Zenodo. https://doi.org/10.5281/zenodo.3264930 (Accessed 1 Aug 2019)

Cunha S, Ferreira J, Marques J, Silva A, Mendes M, Numes L (2011) The Universal Thermal Climate Index case studies at Portuguese meteorological institute, EMS Annual Meeting Abstracts, vol 8, EMS2011-533

Di Napoli C, Barnard C, Prudhomme C, Cloke HL, Pappenberger F (2020) ERA5-HEAT: a global gridded historical dataset of human thermal comfort indices from climate reanalysis. Geosci Data J 00:1-9. https://doi.org/10.1002/gdj3.102

Di Napoli C, Pappenberger F, Cloke HL (2018) Assessing heat-related health risk in Europe via the Universal Thermal Climate Index (UTCI). Int J Biometeorol 62(7):1155-1165. https://doi.org/ 10.1007/s00484-018-1518-2

Di Napoli C, Pappenberger F, Cloke HL (2019) Verification of heat stress thresholds for a healthbased heat-wave definition. J Appl Meteorol Climatol 58:1177-1194. https://doi.org/10.1175/ JAMC-D-18-0246.1

Di Napoli C, Hogan R, Pappenberger F (2020) Mean radiant temperature from global-scale numerical weather prediction models. Int J Biometeorol 64:1233-1245. https://doi.org/10.1007/s00484020-01900-5

Fanger PO (1970) Thermal comfort. Analysis and application in environment engineering. Danish Technical Press, Copenhagen, p 244

Gao C, Kuklane K, Ostergren PO, Kjellstrom T (2018) Occupational heat stress assessment and protective strategies in the context of climate change. Int J Biometeorol 62(3):359-371. https:// doi.org/10.1007/s00484-017-1352-y

KLIMADA Project (2013) Adaptation to climate change in Poland. Republic of Poland, Ministry of the Environment

Krzyżewska A, Dobek M, Domżał-Drzewicka R, Rząca M (2017) Emergency interventions due to weather-related hypothermia. Weather 72:8-12. https://doi.org/10.1002/wea.2926

Heusinkveld B, Sterenborg G, Steeneveld GJ, Attema JJ, Ronda RJ, Holtslag AAM (2017) Smartphone app brings human thermal comfort forecast in your hands. Bull Am Meteor Soc 98:2533-2541. https://doi.org/10.1175/BAMS-D-16-0082.1

Hogan RJ, O'Connor EJ, Illingworth AJ (2009) Verification of cloud-fraction forecasts. Q J R Meteorol Soc 135:1494-1511. https://doi.org/10.1002/qj.481 
Morabito M, Grifoni D, Crisci A, Fibbi L, Orlandini S, Gensini GF, Zipoli G (2014) Might outdoor heat stress be considered a proxy for the unperceivable effect of the ultraviolet-induced risk of erythema in Florence? J Photochem Photobiol 130:338-48. https://doi.org/10.1016/j.jphotobiol. 2013.12.009

Morabito M, Messeri A, Noti P, Casanueva A, Crisci A, Kotlarski S, Orlandini S, Schwierz C, Spirig C, Kingma BRM, Flouris AD, Nybo L (2019) An occupational heat-health warning system for Europe: the HEAT-SHIELD platform. Int J Environ Res Public Health 16(16):2890. https://doi. org/10.3390/2Fijerph16162890

Nastos PT, Matzarakis A (2012) The effect of air temperature and human thermal indices on mortality in Athens, Greece. Theor Appl Climatol 108(3-4):591-599. https://doi.org/10.1007/ s00704-011-0555-0

NIOSH (2016) NIOSH criteria for a recommended standard: occupational exposure to heat and hot environments. Jacklitsch B, Williams WJ, Musolin K, Coca A, Kim J-H, Turner N. Cincinnati, OH: U.S. Department of Health and Human Services, Centers for Disease Control and Prevention, National Institute for Occupational Safety and Health, DHHS (NIOSH) Publication 2016-106

Novák M (2011a) UTCI-first test in the Czech Republic. Prace i Studia Geograficzne, vol 47. Wydział Geografii i Studiów Regionalnych, Uniwersytet Warszawski, Warszawa, pp 319-325

Novák M (2011b) A comparison of an UTCI to some other selected indices. In: Šiška B, Hauptvogl M, Eliašová M (eds) Bioclimate: source and limit of social development, international scientific conference, 6th-9th September 2011, Topolčianky, Slovakia. ISBN 978-80-552-0640-0

Novák M (2013) Use of the UTCI in the Czech Republic. Geogr Pol 86(1):21-28. https://doi.org/ 10.7163/GPol.2013.3

Pappenberger F, Jendritzky G, Staiger H, Dutra E, Di Giuseppe F, Richardson DS, Cloke HL (2015) Global forecasting of thermal health hazards: the skill of probabilistic predictions of the Universal Thermal Climate Index (UTCI). Int J Biometeorol 59(3):311-323. https://doi.org/10. 1007/s00484-014-0843-3

Petersson J, Kuklane K, Gao C (2019) Is there a need to integrate human thermal models with weather forecasts to predict thermal stress? Int J Environ Res Public Health 16(22):4586. https:// doi.org/10.3390/2Fijerph16224586

Rio J, Silva P, Novo I (2018) Automatic forecasts algorithms. VI Simposio Nacional de Predicción, Memorial Antonio Mestre, Madrid, 17-19 September. https://doi.org/10.31978/639-19010-0.187

Romaszko J, Cymes I, Dragańska E, Kuchta R, Glińska-Lewczuk K (2017) Mortality among the homeless: causes and meteorological relationships. PLoS One 12(12):e0189938. https://doi.org/ 10.1371/journal.pone.0189938

Shartova NV, Shaposhnikov DA, Konstantinov PI, Revich BA (2019) Universal thermal climate index (UTCI) applied to determine thresholds for temperature-related mortality. Health Risk Anal 3:83-93. https://doi.org/10.21668/health.risk/2019.3.10.eng

Skutecki R, Jalali R, Dragańska E, Cymes I, Romaszko J, Glińska-Lewczuk K (2019) UTCI as a bio-meteorological tool in the assessment of cold-induced stress as a risk factor for hypertension. Sci Total Environ 688:970-975. https://doi.org/10.1016/j.scitotenv.2019.06.280

Termonia P, Fischer C, Bazile E, Bouyssel F, Brožková R, Bénard P, Bochenek B, Degrauwe D, Derková M, El Khatib R, Hamdi R, Mašek J, Pottier P, Pristov N, Seity Y, Smolíková P, Španiel O, Tudor M, Wang Y, Wittmann C, Joly A (2018) The ALADIN System and its canonical model configurations AROME CY41T1 and ALARO CY40T1. Geosci Model Dev 11:257-281. https:// doi.org/10.5194/gmd-11-257-2018

Thorsson S, Lindberg F, Eliasson I, Holmer B (2007) Different methods for estimating the mean radiant temperature in an outdoor setting. Int J Climatol 27(14):1983-1993. https://doi.org/10. $1002 /$ joc. 1537

Urban A, Kyselý J (2014) Comparison of UTCI with other thermal indices in the assessment of heat and cold effects on cardiovascular mortality in the Czech Republic. Int J Environ Res Public Health 11:952-967. https://doi.org/10.3390/ijerph110100952 
Urban A, Di Napoli C, Cloke HL, Kysely J, Pappenberger F, Sera F, Schneider R, Vicedo-Cabrera AM, Acquaotta F, Ragettli MS, Iniquez C, Tobias A, Indermitte E, Orru H, Jaakkola JJK, Ryti NRI, Pascal M, Huber V, Schneider A, de Donato F, Michelozzi P, Gasparrini A. (2021) Evaluation of the ERA5 reanalysis-based Universal Thermal Climate Index on mortality data in Europe. Environ Res 198:111227. https://doi.org/10.1016/j.envres.2021.111227

VDI 3789 (1994) VDI 3789 Part 2:1994-10: Environmental meteorology-interactions between atmosphere and surfaces-calculation of short-wave and long-wave radiation. Beuth, Berlin, $p$ 52

Vitolo C, Di Napoli C, Di Giuseppe F, Cloke HL, Pappenberger F (2019) Mapping combined wildfire and heat stress hazards to improve evidence-based decision making. Environ Int 127:21-34. https://doi.org/10.1016/j.envint.2019.03.008

Weihs P, Staiger H, Tinz B, Batchvarova E, Rieder H, Vuilleumier L, Maturilli M, Jendritzky G (2012) The uncertainty of UTCI due to uncertainties in the determination of radiation fluxes derived from measured and observed meteorological data. Int J Biometeorol 56(3):537-555. https://doi.org/10.1007/s00484-011-0416-7

WMO (2004) Guidelines on biometeorology and air quality forecasts. WMO/TD No. 1184, PWSNo. 10. Kusch W, Fong HY, Jendritzky G, Jacobsen I. In: Kootval H (ed) Geneva, Switzerland

Open Access This chapter is licensed under the terms of the Creative Commons Attribution 4.0 International License (http://creativecommons.org/licenses/by/4.0/), which permits use, sharing, adaptation, distribution and reproduction in any medium or format, as long as you give appropriate credit to the original author(s) and the source, provide a link to the Creative Commons license and indicate if changes were made.

The images or other third party material in this chapter are included in the chapter's Creative Commons license, unless indicated otherwise in a credit line to the material. If material is not included in the chapter's Creative Commons license and your intended use is not permitted by statutory regulation or exceeds the permitted use, you will need to obtain permission directly from the copyright holder.

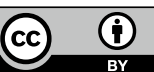

